\title{
Wounds of war in the civilian sector: principles of treatment and pitfalls to avoid (Eur J Trauma Emerg Surg (2014) 40:461-468)
}

\author{
E. E. Donnelly
}

Received: 13 October 2014 / Accepted: 6 November 2014 / Published online: 26 November 2014

(C) Springer-Verlag Berlin Heidelberg 2014

\section{Dear EJTES Editor,}

I am deeply pleased having read in the EJTES August 2014 issue, L. Riddez's paper on: Wounds of war in the civilian sector: principles of treatment and pitfalls to avoid (Eur $\mathbf{J}$ Trauma Emerg Surg (2014) 40:461-468).

In a simple and clear language, the article details and precisely covers every aspect of so-called penetrating war wounds, focusing on what to do and what not to do.

Ballistics, low and high energy wounds, triage, prehospital systems and management, hospital initial assessment, wound follow-up, are all analyzed; direct recommendations and pitfall avoidance on sectorial injuries are addressed, with strict adherence to Advanced Trauma Life Support (ATLS) [1] principles.
My only difference with Dr Riddez, is with his appreciation that this is a short review; this is not so, I believe it is a thorough research paper on management of war wounds, that I recommend should be read by both civilian sector and military war zone surgeons and suggest it could be followed as a future guidelines manual on war wounds, for different scenarios and phases.

Conflict of interest None.

\section{Reference}

1. American College of Surgeons Committee on Trauma. Advanced trauma life support, ATLS, student course manual. 9th ed. Chicago: American College of Surgeons; 2012.

E. E. Donnelly $(\square)$

FACS, Durand Hospital, Buenos Aires, Argentina

e-mail: eedonnelly@intramed.net 